\title{
SUSTAINABLE SOIL MANAGEMENT
}

OLE GREEN, ALEVTINA EVGRAFOVA, SøREN KIRIEGAARD NIELSEN, GARETH T.C. EDWARDS, ANDRÉS VILLA-HENRIKSEN, LIUBAVA ZNOVA, FREDERIK FOLDAGER, LARS JUHL MUNKHOLM AND TOMMY DALGAARD

DCA REPORT NO. $121 \cdot$ MAY 2018

AARHUS
UNIVERSITY

DCA - DANISH CENTRE FOR FOOD AND AGRICULTURE

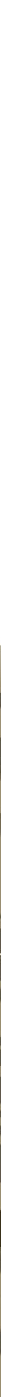




\section{Sustainable Soil Management}

\section{Supplementary information and clarifications (October 2019)}

In an effort to ensure that this report complies with Aarhus University's guidelines for transparency and open declaration of external cooperation, the following supplementary information and clarifications have been prepared in collaboration between the researcher ( $s$ ) and the faculty management at Science and Technology:

The report was prepared for the annual meeting in the SoilCare project in 2018. SoilCare is a Horizon 2020 funded research project where Aarhus University and AgroIntelli are among the partners. Rudi Hessel, Wageningen University, is coordinator of the Soil Care-project.

AgroIntelli's role in the SoilCare project is as company partner.

AgroIntelli has contributed to the report with knowledge about sensor technology. This knowledge has also been developed in public financed projects (Innovation Fund Denmark and EU Horizon 2020)

The report is based on earlier published peer reviewed material, including three Ph.D. dissertations.

The report is compiled by Ole Green. Ole Green the owner of AgroIntelli and an adjunct professor at Aarhus University. All co-authors from AU and AgroIntelli have read and approved the content of the report.

The authors have contributed with the following elements in the report:

- Ole Green, AgroIntelli and AU: Editor and main author

- Alevtina Egrafova, AgroIntelli: Research project results and information

- Søren Kirkegaard Nielsen, AgroIntelli: Results based on previous PhD project

- Gareth. T. C. Edwards, AgroIntelli: Research project results

- Andrés Villa-Henriksen, AgroIntelli and AU: Research project results

- Luibva Znova, AgroIntelli: Research project results

- Frederik Foldager, AgroIntelli and AU: Research project results

- Lars Juhl Munkholm, AU: Research project results and review

- Tommy Dalgaard, AU: Research project results and description of Agroecology related work 


\section{SUSTAINABLE SOIL MANAGEMENT}

DCA REPORT NO. $121 \cdot$ MAY 2018

Ole Green ${ }^{1,2}$, Alevtina Evgrafova', Søren Kirkegaard Nielsen', Gareth T.C. Edwards', Andrés Villa-Henriksen ${ }^{1,3}$, Liubava Znova', Frederik Foldager ${ }^{1,3}$, Lars Juhl Munkholm² and Tommy Dalgaard ${ }^{2}$

Agro Intelligence ApS 1

Agro Food Park 13

DK-8200 Aarhus $N$

Denmark

Aarhus University ${ }^{2}$

Department of Agroecology

Blichers Allé 20

Tjele

Denmark

Aarhus University ${ }^{3}$

Department of Engineering

Navitas Aarhus

Denmark 


\section{SUSTAINABLE SOIL MANAGEMENT}

Series:

No.:

Authors:

Publisher:

Co-funded

by:

Photo:

Print:

Year of issue:
DCA report

121

Ole Green, Alevtina Evgrafova, Søren Kirkegaard Nielsen, Gareth T.C. Edwards, Andrés Villa-Henriksen, Liubava Znova, Frederik Foldager, Lars Juhl Munkholm and Tommy Dalgaard

DCA - Danish Centre for Food and Agriculture, Blichers Allé 20, PO box 50, DK-8830 Tjele. Tel. 8715 1248, e-mail: dca@au.dk, web: www.dca.au.dk

European Commission, Directorate General for Research under Framework Programme HORIZON 2020 Programme under grant agreement no 677407 (SOILCARE project).

All illustrations are made by Ole Green and Keld Bertelsen and owned by AGROINTELLI (http://agrointelli.com). All reproduction of these illustrations must be made with complete reference to this report.

www.digisource.dk

2018

Copying permitted with proper citing of source

ISBN:

Printed version 978-87-93643-54-3, elektronic version 978-87-93643-55-0

ISSN:

$2245-1684$

Reports can be freely downloaded from www.dca.au.dk

\section{Scientific report}

The reports contain mainly the final reportings of research projects, scientific reviews, knowledge syntheses, commissioned work for authorities, technical assessments, guidelines, etc. 


\section{Preface}

The motivation of this work is to raise conservation and environmental awareness among advanced farmers, consultants, NGOs and policy makers of the opportunities of new technological innovations and their applications for sustainable intensification of arable farming systems, following a sustainable soil management strategy.

By improving farmers' awareness of importance to integrate sustainable and resilient management practices and suitable technologies in arable ecosystems across the globe, it would be possible to maximize production and income in a more sustainable way, thus, diminish socio-economic issues as well as maintain and improve food and soil quality in both short- and long-terms. By implementing sustainable soil management practices, it is possible to address global issues such as to improve food and water security, reduce negative environmental impacts and human health issues induced by agricultural activities as well as contribute to biodiversity preservation.

\section{Niels Halberg}

Director DCA - Danish Centre for Food and Agriculture 


\section{Table of Contents}

Preface

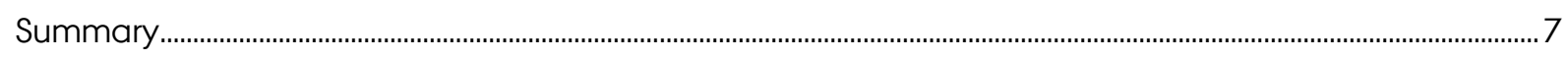

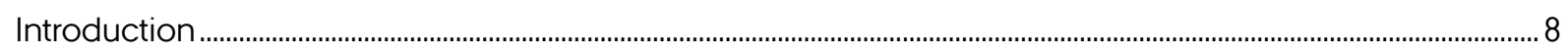

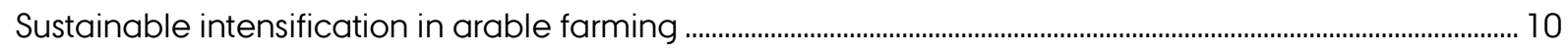

Short recommendations for stakeholders in order to achieve sustainable agricultural development.... 11

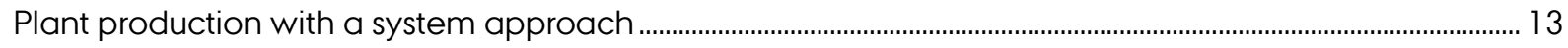

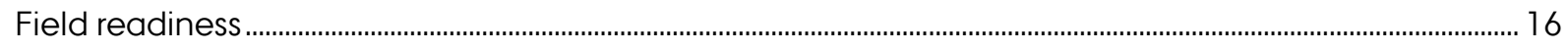

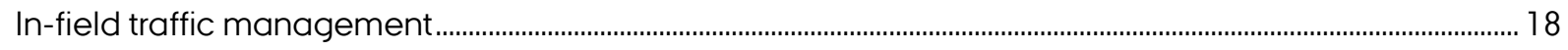

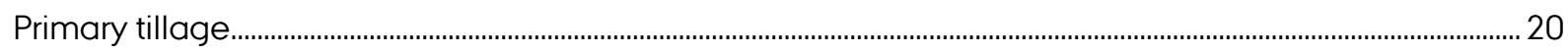

The site-specific depth-controlled mouldboard plough .................................................................................... 20

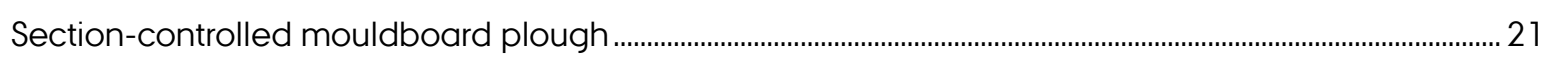

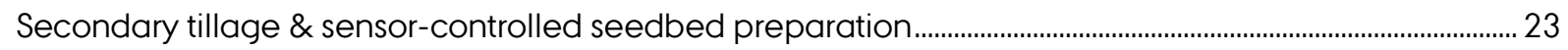

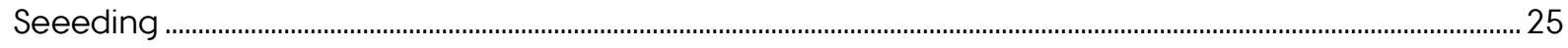

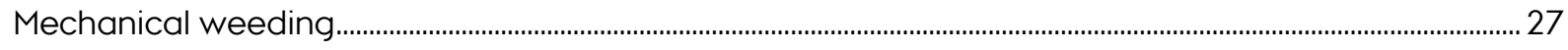

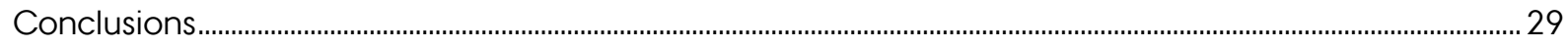

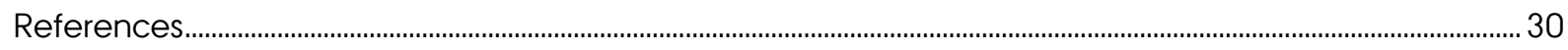




\section{Summary}

This report provides the insights on knowledge and technical aspects of sustainable soil management practices by adjusting and controlling agricultural machinery and tools based on the site- and fieldspecific parameters. Agricultural machinery can be used for collecting more information on agricultural lands by implementing various sensors that will allow measuring current and estimating future field and crop parameters, which is a direct input to optimize agricultural machinery's performance.

This report illustrates the importance to combine a system approach for plant production by assessing field readiness, managing in-field traffic management, implementing the site-specific controlled as well as sensor-controlled seedbed preparation, seeding and weeding. This approach will allow reducing operational costs and minimising negative environmental impacts. 


\section{Introduction}

Soil is a vital and non-renewable resource that provides multiple ecosystem services (e.g. water purification) and functions (e.g. biomass production). Although soil formation requires long time, it is a fragile environment that can be destroyed in a short period of time such as a few years. Soil degradation is recognized as a serious problem worldwide, resulting in losses of thousands of square kilometres of agricultural land each year (RECARE and SOILCARE). Although soil quality could be decreased as a result of soil degradation and soil compaction induced by natural forces, the major soil threats in Europe are mostly driven by anthropogenic activities. The latter includes inappropriate soil management practices that contribute and accelerate soil degradation processes as well as contribute to the release of greenhouse gases into the atmosphere, thus, creating a positive feedback loop. Moreover, a combination of both climate change and unsustainable agricultural activities and land use changes could lead to other soil threats, which were identified as soil erosion by water or wind, decline of soil organic matter, soil compaction, soil sealing, soil contamination, flooding and landslides, salinization, desertification, and the loss of soil biodiversity (European Commision, 2005).

Intensive tillage operations are important drivers of wind and water soil erosion, thus, leading to decrease of soil stability as a result of lower soil aggregate stability. Frequent field traffic of heavy machinery leads to crop damage and soil compaction of both the topsoil and the subsoil, thus, soil infiltration capacity is reduced and surface runoff and/or inhibited plant growth may occur. In addition to the direct impact of soil threats as a contribution to soil degradation, soil threats also amplify impacts as a result of their interactions. For example, soil compaction has a large effect on soil erosion by water and wind, which itself results in desertification and loss of topsoil, which is the most fertile part, leading to loss of productivity (Figure 1).

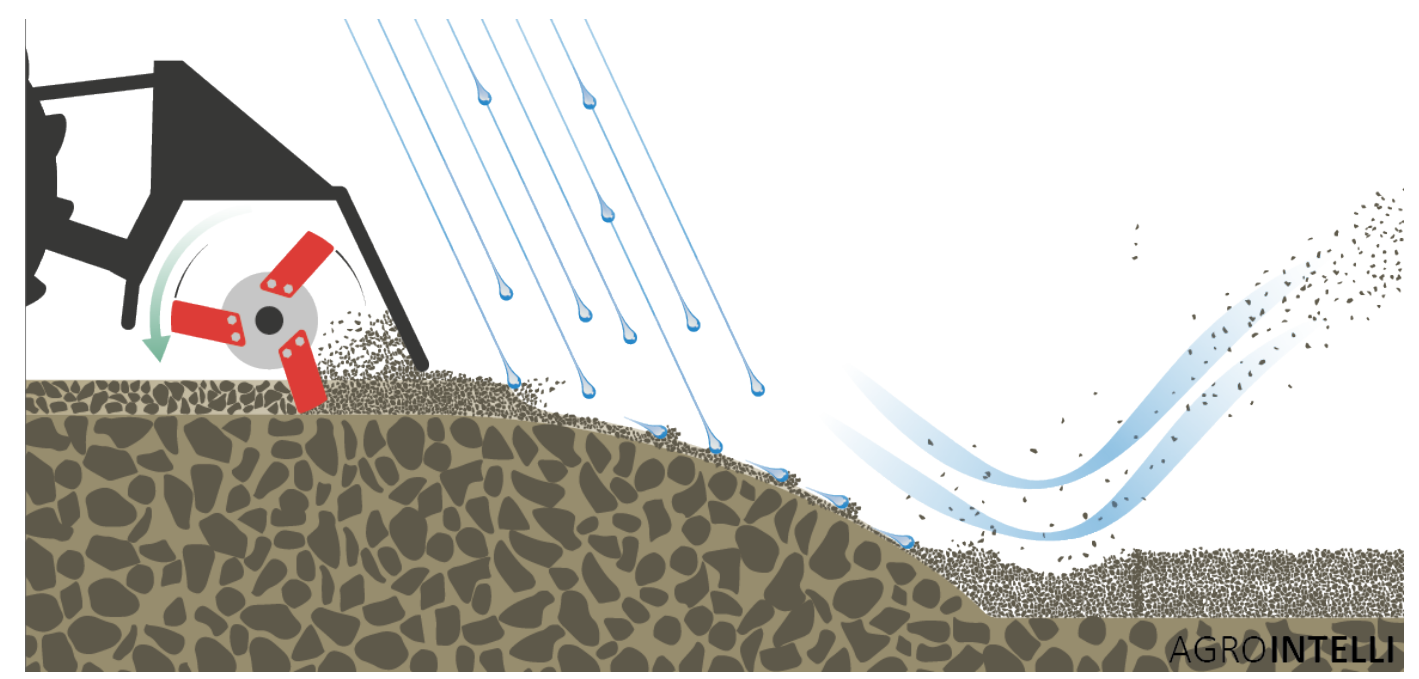

Figure 1. Intensive tillage can lead to an increasing risk of water and wind-induced soil erosion. 
Therefore, agricultural mitigation and adaptation strategies as well as sustainable soil management practices should be defined and implemented in order to reduce and prevent further associated environmental and health issues in Europe as well as to reduce negative impacts of agriculture, soil threats and soil degradation. 


\section{Sustainable intensification in arable farming}

The continuing population and economic growth combined with accelerating resource scarcity (i.e. clean water and fertile agricultural lands) and climate change-induced vulnerability led to agricultural intensification. The latter was mostly achieved by transforming forest, wetland, and grassland into farmlands and based on further business as usual scenarios focusing on the intensification of agricultural inputs (i.e. fertilizers, pesticides, and heavy machinery) in order to obtain higher outputs. However, such approaches were associated with high negative environmental impacts (i.e. land and soil degradation) and, thereby, lower yielding and food nutrient quality. In consequence, the concept of sustainable intensification in arable farming was emerged as a response to the global food security challenge and necessity to define suitable mitigation and adaptation agricultural strategies for global change. This concept is defined as a simultaneous improvement of crop productivity and food quality, while negative environmental impacts are being reduced by implementing suitable agricultural management practices and technologies (Garnett \& Godfray, 2012). The term sustainability was defined in the Brundtland Report (World Commission on Environment and Development, 1987) as "meeting the needs of the present generation without compromising the ability of future generations to meet their needs". The global agreements such as Zero Net Land Degradation (i.e. water, food and energy security) and Zero Hunger Challenge (i.e. hunger and poverty eradication) played an important role in order to raise awareness of sustainability issues across the globe.

In agricultural sector, the goals of sustainable intensification can be reached by defining new approaches and integrating suitable technologies in agricultural operations, especially such as automation and agricultural sensing, while the equal attention on economic, environmental, and social aspects of sustainable agricultural intensification is required. Despite the fact that economic aspect of agricultural development has been always prioritized, policy-makers, agribusiness, and farmers need to set a dialog in order to define socio-eco-economic indicators, policies, and farming adaptation strategies in order to follow long-term sustainable agricultural development in order to secure the natural capital (i.e. soils, water, forests etc.). One of the most common frameworks for sustainable farming are found within agroecology, biodynamic and organic production systems, integrated and precision farming, and conservation agriculture. The integration of certain systems, machinery, and management practices is mostly depending on market availability, user-friendly operating system, and associated potential economic advantages. 


\section{Short recommendations for stakeholders in order to achieve sustainable agricultural development}

A successful implementation of sustainable agricultural intensification strategies and practices include the integration of economic, environmental and social aspects and can be achieved by implementing the mentioned-below actions that would be done in cooperation between farmers, scientists, and policy-makers. The mentioned-below suggestions provide some ideas how to integrate sustainable agricultural approaches at different levels. However, the authors understand the necessity to conduct further research, including a stakeholder analysis in order to define the most efficient and suitable strategies for different types of stakeholders.

- Implementing suitable technologies after assessing land capability (e.g. erosion potential, soil fertility) using various approaches:

o Variable Rate Application;

o Fleet logistics optimization tool;

o Farm Management Information Systems;

o Various sensors (e.g. RGB and infrared cameras, soil sensors).

- Shaping achievable sustainable farming adaptation strategies and policies based on scientific findings and technologies:

o Prevention and management of soil erosion;

o Prevention and management of soil compaction;

o Implementation of the site-specific precision farming management practices for tillage operations;

- Setting case studies to assess various sustainable soil management techniques;

- Developing a suitable governmental/private subsidy scheme that would assist with:

o Creating a suitable land use planning;

o Promoting gender equality;

- Adapting agribusiness certification and farming practices;

o Land ownership or long-term renting;

o Optimised tax scheme;

o Providing opportunities for education and vocational trainings;

o Stimulating migration to rural and transition areas.

- Supporting education for farmers and agribusiness partners as well as outreach by:

o Organizing workshops and exhibitions with a possibility to conduct surveys;

o Updating stakeholders on the latest suitable practices;

o Supporting farmer-to-farmer concept;

o Providing educational brochures with important facts and techniques possible to apply in order to maximise profit, while reducing negative environmental impacts. 
- Providing energy reduction recommendations based on:

o Setting optimized machinery operational plan;

o Automatization and auto-steering based on sensors.

- Setting associations to represent private agricultural sector (i.e. small-scale stakeholders, farmers, and agribusiness) economically, politically and socially:

o Promoting gender equality;

o Organizing surveys in order to monitor the situation in agricultural sector;

o Preparing recommendations on bureaucracy and administrative costs reduction;

o Distributing information and updates on sustainable practices to farmers via newsletters as well as to keep motivation high to follow the practices by sharing successful examples;

o Creating a website and/or a mobile application in order to be more efficient with previously-mentioned points. 


\section{Plant production with a system approach}

Sustainable soil management includes the identification of suitable crop distribution, timing, and applied management practices and techniques for both food and biofuel plant production in order to protect and improve the resilience of arable ecosystems. In order to enhance resilience of arable ecosystems, regular and revising planning and monitoring of the between- and within-ecosystem diversity and interactions, ecosystem properties and its adaptability must be conducted at the characteristic scale. One of the main principles of intelligent or smart farming is to identify the significant within-field spatial and temporal variability and its drivers in order to optimise soil and crop management. Therefore, the desired system inputs, operational space, and time settings can be optimized by considering the spatial scale at which decisions for each agricultural operation are made (Figure 2). In order to adjust the sitespecific and dynamic field operations as well as increase energy efficiency, the vehicles should be equipped with various functional sensors, electric actuators and, potentially, with Internet of Things (loT) technologies, thus, enabling the feedback processing and on-the-go control and adjustments. The integration of mentioned-above technologies will allow collecting data that describes the within-field variations needed for both on-going and future field operations and planning. Hence, soil and crops will be managed sustainably and the return on investments will be maximized.

The implement-, tractor- and/or drone-mounted cameras and sensors, stationary soil sensors and satellite images can be used as multiple measurement sources to monitor and predict environmental conditions, biodiversity value, soil-plant-atmosphere relationships, crop development and yields (Figure 3). For example, a tractor and a sprayer or a fertilizer spreader equipped with a high accuracy positioning system can be used for section control of the application of chemicals or nutrients, which allows including the site-specific variability for mapping and modelling of environmental conditions, previous field operations, crop yields and direct and indirect threats. 


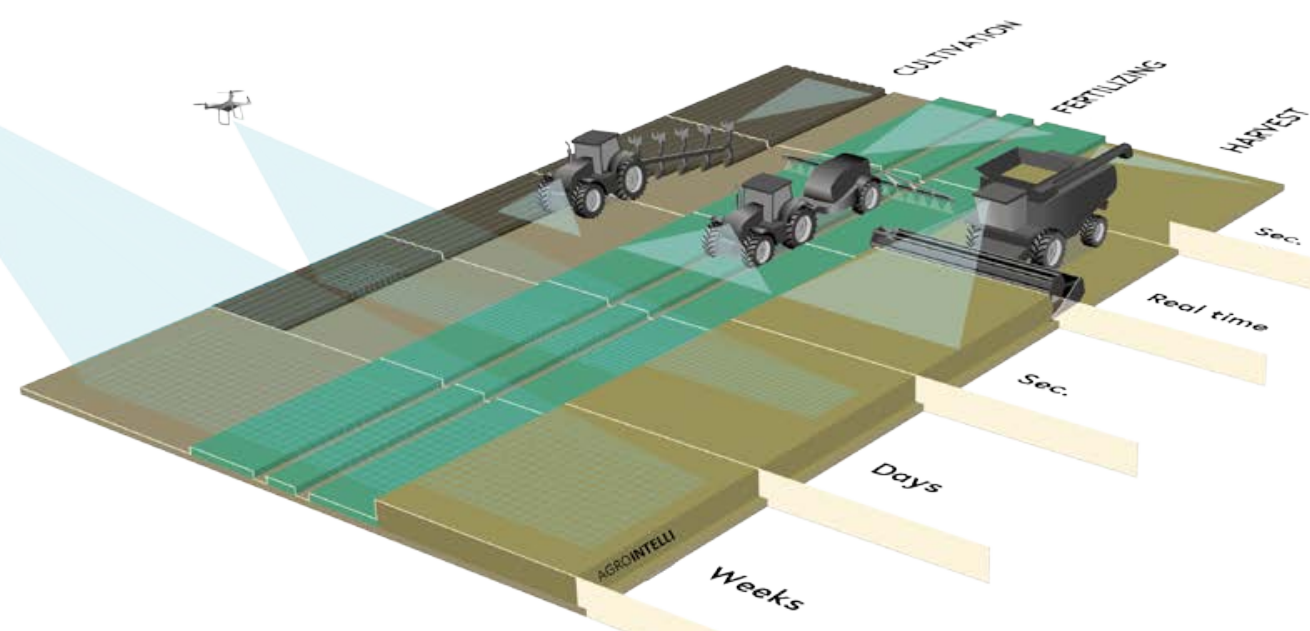

Figure 2. The use of site-specific information will enable a new generation of plant production with a system approach.

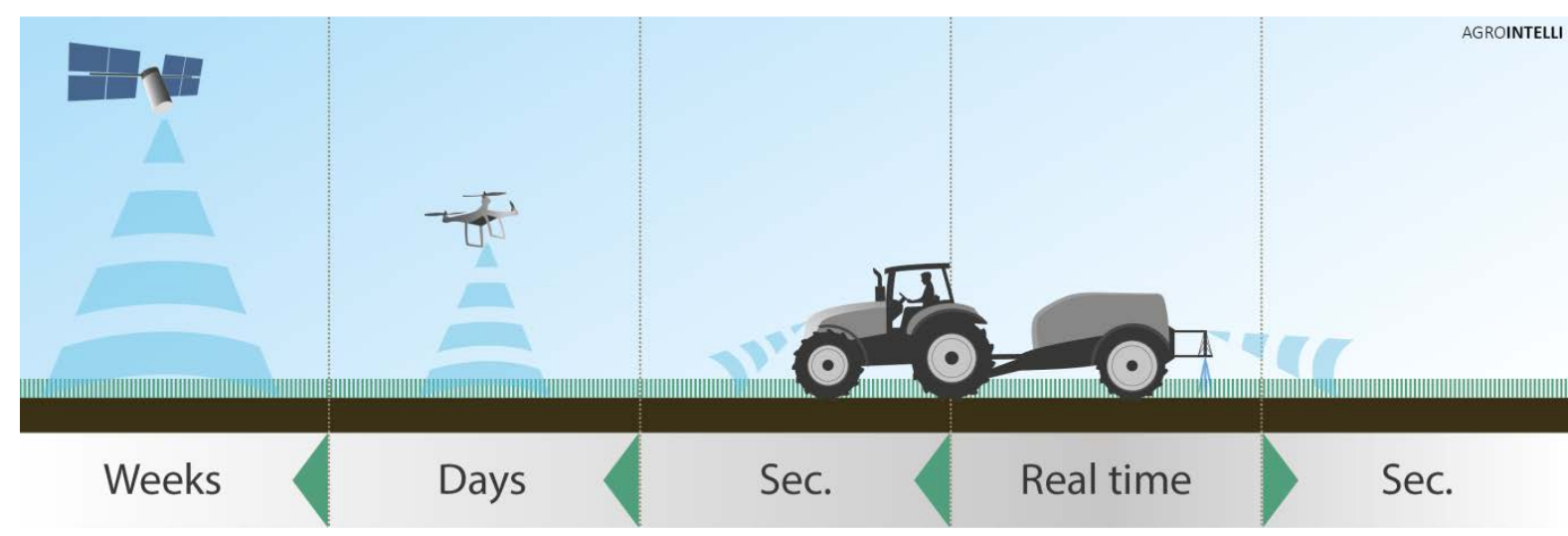

Figure 3. Sensor-based agricultural application, which allows collecting and analysing data at various spatial and temporal scales.

The associate challenge with the smart farming concept is how to motivate stakeholders to allow collecting farming data and assure that the set of rules and regulations for data collection (e.g. format, accuracy), sharing (e.g. availability, ownership), storage (e.g. safety, compatibility), and analysis will be followed accordingly. Farming data can be used to predict and support future suitable farming operations and related policies as well as to optimise a current business model for achieving more sustainable plant production and soil management. It is understandable why farmers might have some scepticism towards data collecting and sharing as it might serve as certain control on their performance 
and activities. However, the site-specific soil management can provide new business and networking opportunities as well as improved policy settings as a result of improved agricultural site-specific controlled operations - either tillage depth control, spraying or seeding. For example, seedbed preparation and seeding can be controlled by the site-specific operations in order to optimise crop establishment, hence, increase crop yields. 


\section{Field readiness}

Field readiness is a parameter that provides information on the status of a field's soil and its crop conditions in relation to a specific operation or set of operations. It can be used in order to plan and conduct on-going and future field operations with greater precision and, thus, at the lowest cost and associated damages (Edwards, 2015). The field's readiness is defined as a situation with favourable soil and environmental conditions for a certain field operation (i.e. workability) and the lowest negative impacts induced by in-field traffic operations (i.e. trafficability). Furthermore, Farm Management Information Systems need to integrate methods evaluating both workability and trafficability simultaneously, thus, it would be possible to control and cause minimum or reversible ecosystem alteration (e.g. soil structure changes) while operating in the field.

The field trafficability can be estimated using models or web-based tools, e.g. FRIDA (Per Schjønning, Lamandé, Tøgersen, Arvidsson, \& Keller, 2008) or Terranimo (https: // www. terranimo. dk). The former evaluates the soil stress distribution along the tyre foot print based on the tire properties and tire pressure, while the latter provides a simplified report indicating the risk of soil compaction (i.e. soil compaction index) within the soil profile based on the tire-soil contact area for specified tire characteristics and distribution of the total load between front and rear axles. For example, top- and subsoil compaction that decreases crop yields can be avoided or minimized if field parameters are taken into account as well as if lower load per wheel or/and higher soil-wheel contact area are introduced. In order to maximize the field trafficability, it is recommended to limit the vertical stress within the soil profile and not exceed the limit of $50 \mathrm{kPa}$ below $50 \mathrm{~cm}$ (P. Schjønning, Lamandé, Keller, Pedersen, \& Stettler, 2012). Hence, farmers can easily evaluate the soil trafficability, which will be acceptable if the soil stress induced by in-field traffic is estimated lower than the critical point leading to soil compaction.

In order to achieve efficient and sustainable tillage performance, the field workability is defined by defining a combination of optimal soil water content and optimal soil temperature, which will be specified for each agricultural operation. The optimal soil water content is defined by the range between the upper and lower soil moisture limits, which can be found for different soil types using soil databases or a pedotransfer function. The optimal soil temperature is defined for each crop in order to obtain high crop emergence rates as well as the sum of active temperature could be used to determine the optimal harvest date.

Furthermore, the spatial and temporal variability of soil and crop properties at different periods can be estimated using soil mapping and geostatistical interpolation techniques, proximal soil sensing, soil spectrometry, electromagnetic induction, and aerial photography. Furthermore, crop system models such as APES (Donatelli et al., 2010), DSSAT (Jones et al., 2003) and DAISY (Abrahamsen \& Hansen, 
2000) are used in order to estimate current and future field conditions based on previously recorded field data. 


\section{In-field traffic management}

In order to improve energy use, reduce operational costs and minimise negative environmental impacts (e.g. soil compaction) induced by intensive heavy-machinery traffic, it is necessary to define and implement suitable operational management strategies. Different strategies have been proposed for infield traffic management with emphasis on: (i) the vehicle or implement, e.g. tyre inflation regulation on the go via tyre pressure monitoring system as well as the use of lighter and/or smaller autonomous selfpropelled implements (Green et al., 2014); (ii) on-land ploughing instead of in-furrow ploughing; (iii) soil conditions, e.g. soil readiness modelling or optimised route planning in order to reduce soil compaction (Figure 4). While some of these strategies are already widely known and adopted by concerned farmers, others are still needed further development and strategic implementation. Considerable attention has been paid to optimised route planning as the strategy that can mitigate soil compaction issues and minimise operational time and costs, hence, following sustainable soil management practices as well as be easily combined with other strategies for manging in-field traffic.

The driving route in the field has traditionally been based on the decision capabilities of the vehicle operators, i.e. the driver decides on the best route to complete a field operation in a minimal time or based on some criteria stated by the farmer, e.g. wildlife avoidance planning. However, current research (Bochtis, Sørensen, \& Busato, 2014) and industrial products (Edwards et al., 2017) are developing systems for optimising route planning automatically. Optimised route planning calculates an optimised route for each field adaptively according to the vehicles behaviour using combinatorial optimisation algorithms. The criteria used for the optimisation can include, besides the reduction of operational time, geo-referenced information that can be used for the variable rate application or/and section control. In order to utilise geo-referenced information and achieve higher farming precision by taking the withinfield spatial and temporal variability into account, Global Navigation Satellite System (GNSS) technologies should be used during field operations. Thus, the in-field optimisation can be achieved by simulating planned agricultural operations using the algorithms based on the predictions of the shortest total, headland, and refill timing and distances, soil compaction, while the site-specific field characteristics and agricultural applications (e.g. fertilizer) and features of the fleet vehicles (e.g. tank and carrying capacities) are taken into account. Moreover, optimised route planning can be applied to various agricultural operations and, especially, valuable during the operations with intensive heavy traffic such as slurry application or harvesting, hence, reducing the negative impacts of traffic intensity. Furthermore, auto-steering systems will improve the operational performance as this system will allow following the path and adapting more precisely to the spatial variability than a traditional human-based steering. 

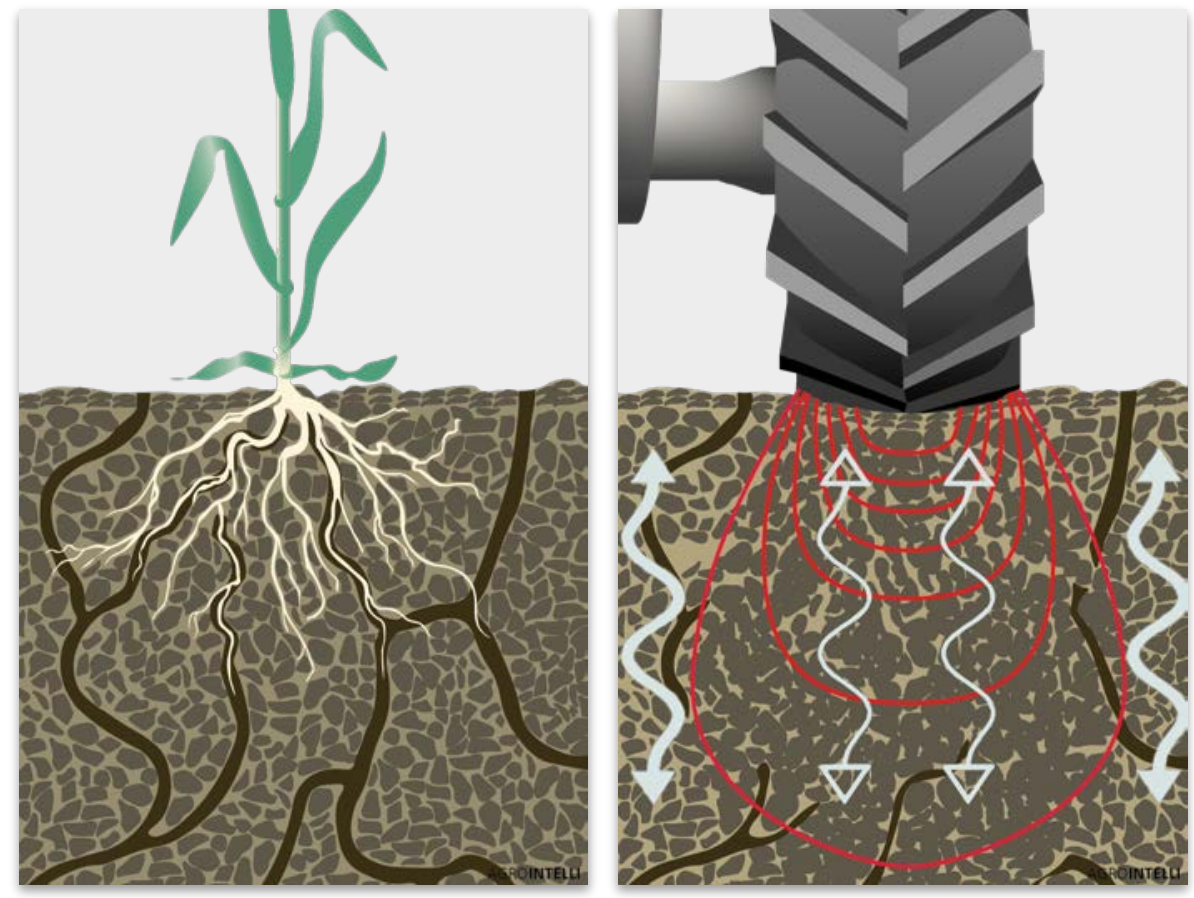

Figure 4. Desired plant development and undesired topsoil compaction induced by in-field traffic, especially after primary tillage.

A fleet logistics optimization tool can also include other optimisation criteria such as the operational speed, turning trajectory, however, if traffic intensity is a main parameter for route optimisation, the operational distance and time will be significantly reduced as the number of passes per area as well as the total weight by traffic per area (both accumulated and at the specific time) can be reduced. Moreover, the optimal strategy in order to follow sustainable soil management practices would be combining as many strategies as possible as well as finding a possibility to combine various operational functions, usually provided by multiple vehicles, in one vehicle with field data recording. The data, collected using agricultural vehicles, can be shared using Internet of Things (loT) technologies and will provide valuable information for soil management practices and following operations. Thus, full automation of field operations can provide even more accurate measures for reducing production costs while operating in an environmentally sustainable manner, e.g. optimising fleets of light-weighted robots for most, if not all, field operations. 


\section{Primary tillage}

Primary tillage is performed by disc, tine or mouldboard ploughs in order to prepare soil for plant production by reducing topsoil compaction as well as conducting weed control and incorporating plant residues, thus, minimizing agricultural inputs such as fertilizers or pesticides. In most cases, ploughing depth and width can be adjusted only manually during field work. Hence, plough settings will depend mostly on farmer's experience as well as operational time and work load for tractor-drivers will be higher. In addition, tillage operations were estimated between $33 \%$ to $48 \%$ of the total energy used during crop establishment (Dalgaard et al., 2002, Sartori et al., 2005). As one of the main foci of sustainable soil management is to reduce negative environmental impacts and fuel consumption during agricultural operations, automatic setting for tillage and other operations would be desirable. The use of sensors and spatial and temporal data analysis enables the optimization of primary tillage operation by including the within-field spatio-temporal variation (i.e. soil properties or residue incorporation). For example, weed maps can be included in order to increase accuracy for weed control using the site-specific optimized plough depths (Figure 5) as well as the site-specific operational depth, cutting edge and plough surface can be set for measured field conditions (e.g. soil moisture).

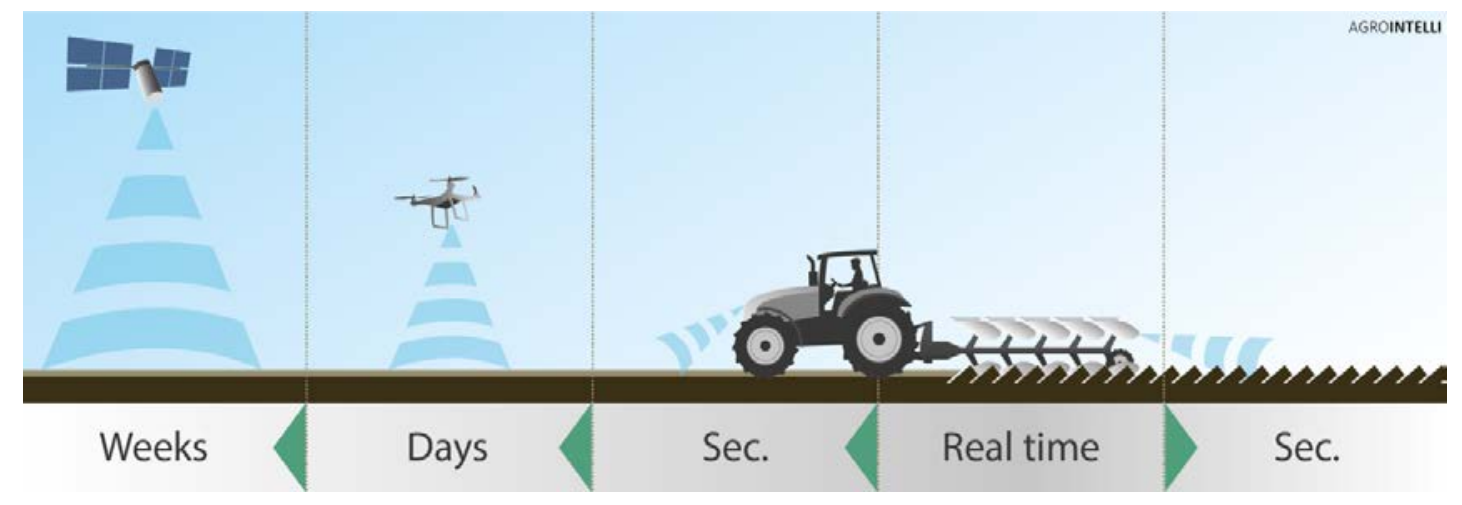

Figure 5. Sensor-based primary tillage operation, which allows implementing and collecting data at various spatial and temporal scales.

\section{The site-specific depth-controlled mouldboard plough}

Recent optimisation strategies for mouldboard ploughing are based on the automation and use of suitable ploughing depth as well as appropriate plough shape and surfaces in order to reduce friction and resistance forces (Figure 6). Although scientific studies showed a variation in crop yield responses to plough depths, it was specified that crop yields will be either similar or higher, especially for silty soils if plough depth is reduced to $15-20 \mathrm{~cm}$ comparing when the operational depths were set at $22-28 \mathrm{~cm}$ (Guul-Simonsen et al., 2002; Inge Håkansson et al., 1998), while energy use efficiency will be improved considerably. Though, weed propagation should be controlled additionally, especially for sandy soils using occasional deep (i.e. $25 \mathrm{~cm}$ ) ploughing or other weed control techniques. In addition, the 
combination of shallow and deep ploughing also diminishes tillage pan compaction issues (GuulSimonsen et al., 2002; Natsis, Papadakis, \& Pitsilis, 1999). Precisely, the site-specific depth-controlled mouldboard plough significantly reduce energy and fuel consumption by $56 \%$ and $34 \%$ to $45 \%$ compared to conventional tillage (Keskin et al., 201 1; Raper et al., 2005).

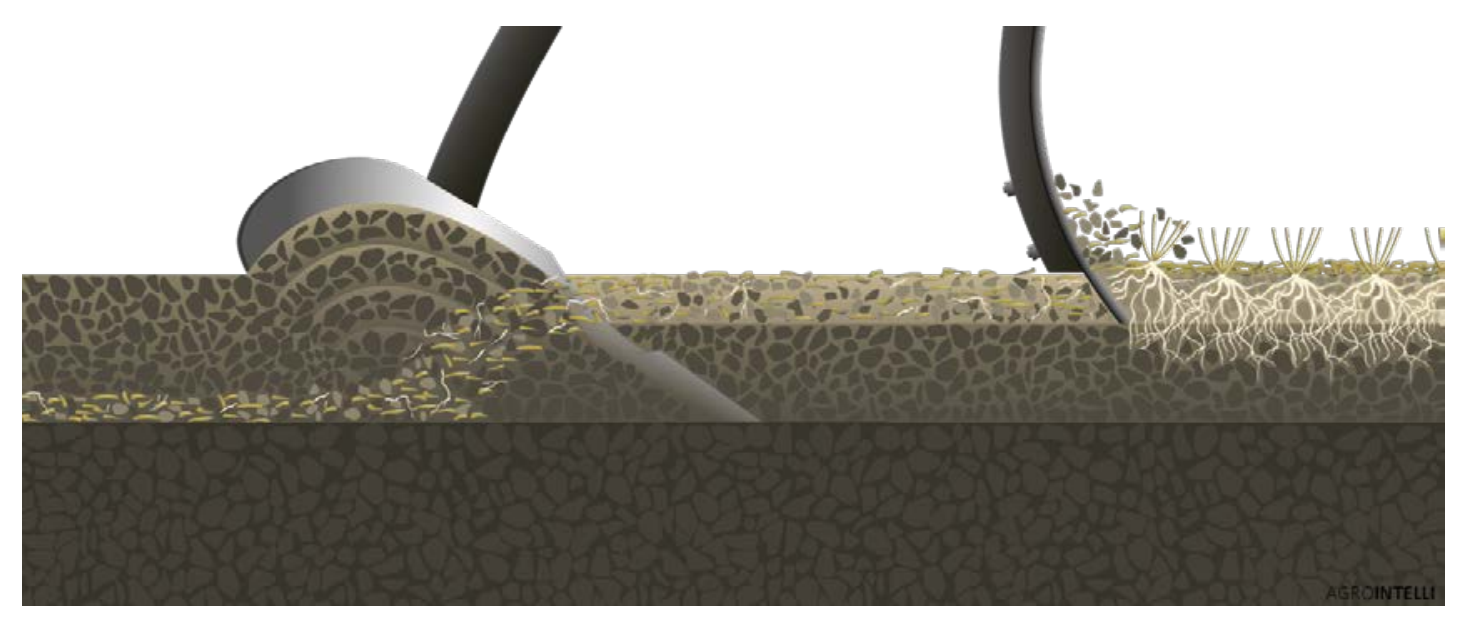

Figure 6. Shallow depth-controlled mouldboard ploughing approach can reduce fuel consumption and negative environmental impacts, while crop yields remain or not significantly affected.

\section{Section-controlled mouldboard plough}

A homogeneous seedbed is one of the prerequisites for the successful crop establishment (i.e. higher crop yields), which can be achieved more rapidly if primary tillage is conducted using the most efficient approach. This means that the intensity of required secondary tillage and/or herbicide applications can be reduced; therefore, the costs and impacts can be minimized as well. However, mouldboard ploughing is especially challenging in order to achieve a uniform seedbed in the intermixing zone (i.e. between headlands and a mainland) by conducting the correct interface and can be associated uneven residue incorporation and weed control. This challenge occurs both when the plough is being elevated and lowered in the headlands, forming an inconsistent tillage operation and undesirable triangular shapes of un-ploughed segments (Figure 7a). This leads to overlapping operations when ploughing the headland perpendicularly to the mainland, which also are time- and energy-consuming and increases the wear of the plough. Poor soil inversion and re-growth of weed is typically seen in the headlands due to the overlap, which may cause further issues during seeding due to the fact that residue and weed are left on the soil surface, hence, additional pesticide application might be required for a beneficial weed control. The latter is especially a concern in organic farming systems, where large lift mounted ploughs are mainly used for pest control. 
One approach to conduct the site-specific tillage is the use of GNSS-based section control system for mouldboard plough share, which aligns a virtual straight line in the headland. By introducing this concept, the ploughing operation at the interface area between the headlands and the main working area will be significantly improved as the operation starts nearly perpendicularly to the main working area and allowing reducing the overlapping area (Figure 7b). The overlapped area for a five-furrow plough will be reduced by up to $80 \%$ by introducing individual lift and lowering system for each plough share, as the percentage of the reduced overlapping area can be calculated as ( 1 - ( $\left.A_{s c} / A_{n s}\right) 100$ ).
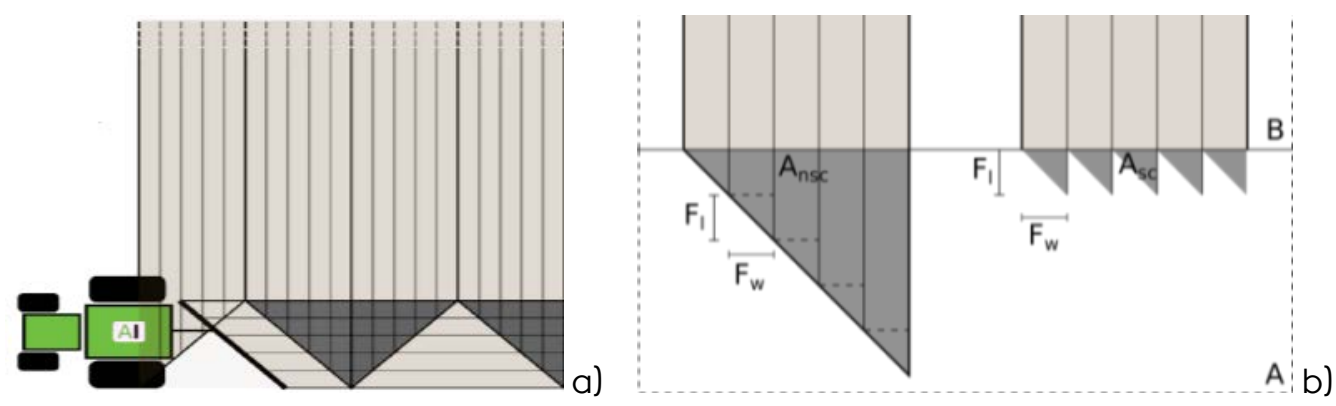

Figure 7. The concept of conventional ploughing area (a) and two ploughing patterns without $\left(A_{n s c}\right)$

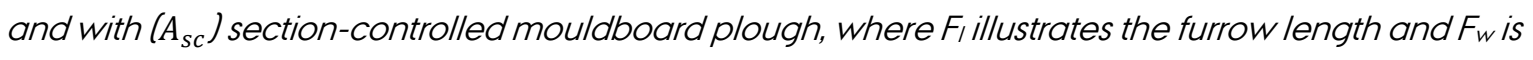
the furrow width (b) (used with permission Nielsen, 2017, PhD Thesis).

Furthermore, on-the-go deactivation of individually-controlled sections combined with a hydraulic stone release system can be used in order to reduce the overlapping area as well as to improve wedge operations when finalizing the mainland of the field instead of reducing the operational width. By deactivating one section, such a system can also be used as a new traction force reduction control system and applied for hilly areas as more traction force is needed uphill than downhill. These systems can be controlled manually by the operator or automatically as combined with some background maps. The number of implemented sections can be determined beforehand in the headlands or changed onthe-go in the main working area if more traction force is unexpectedly needed. In general, such a section-controlled system will improve ploughing performance (i.e. more homogeneous) in the interface and wedge operations as well as can be used for controlling the need traction force. The site-specific section-controlled system on a mouldboard plough improves the operation quality by creating a more homogeneous seedbed and, thus, improving conditions for crop establishment. 


\section{Secondary tillage \& sensor-controlled seedbed preparation}

Secondary tillage can be conducted using different implements such as discs, spring-tine harrows, power harrows or rotavators in order to prepare the seedbed after primary tillage by loosening the topsoil to a controlled depth, which is defined for each plant species. This operation should provide a homogenous loose seedbed (1-5 mm, Russell, 1961) with minimal depth variations and a firm moist bottom in order to provide the desired conditions for a quick germination (Figure 8). Furthermore, more attention should be given to soil structural stability, soil permeability and aggregate size distribution achieved after secondary tillage as this parameter has significant effect on crop development (Brennan \& Leap, 2014; Inge Håkansson et al., 2002). Intensive tillage can create a loose seedbed with small aggregates, hence, making the seedbed more vulnerable to wind- and water-induced erosion and soil compaction, especially during operations by modern tractors with high power and power take off (PTO) harrows. Whereas, large soil aggregates might lead to increased seedbed evaporation and seed heat transfer. Finally, the homogeneity of the seedbed and crop establishment are also important for reducing the risk of pesticide leaching(Petersen et al., 2016) (Petersen et al., 2016) and optimisation of fuel consumption.

An automatic site-specific sensing plays a key role in achieving a homogeneous seedbed by equipping a seedbed cultivator with a vision system (e.g. laser scanners) and image analysis unit, which enabling to control aggregate size distribution, thus, the seedbed quality in real-time as well as to obtain operational data for further data analysis, mapping and recommendations (Figure 9) (Jensen, Karstoft, Green, \& Munkholm, 2017).

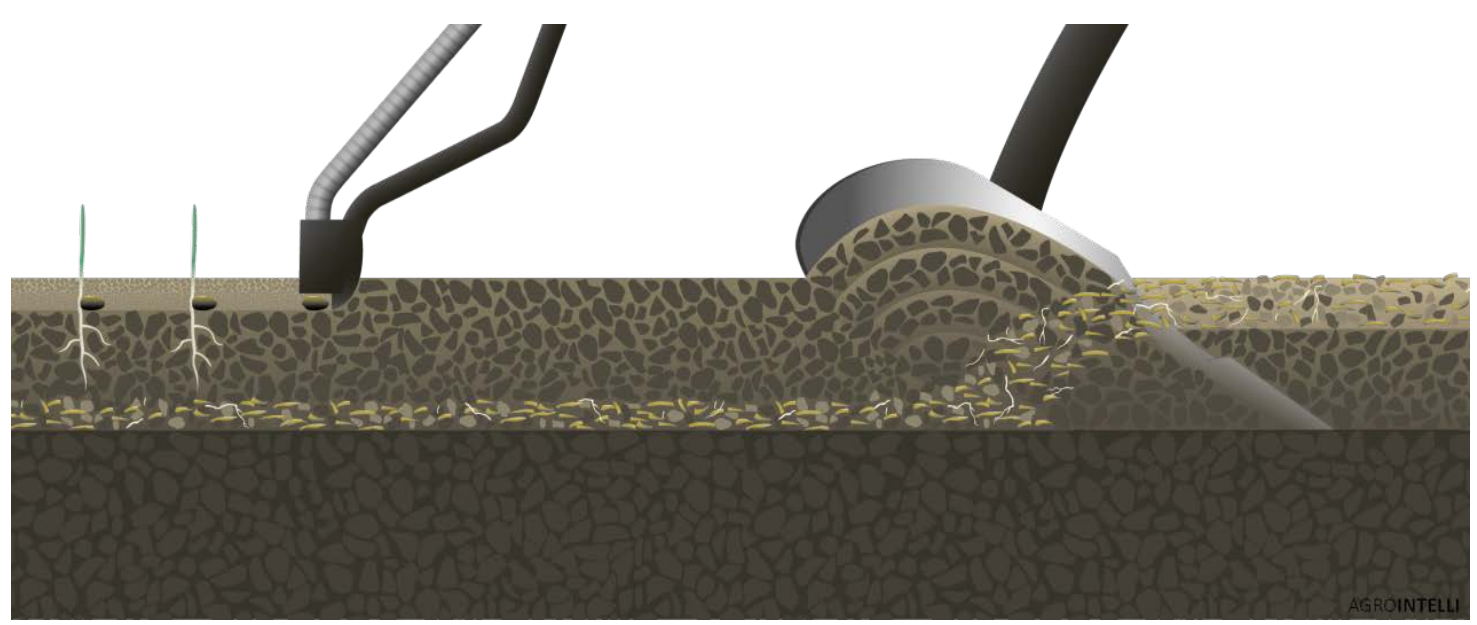

Figure 8. The simultaneous incorporation of plant residues from the soil surface and seeding at a consistent depth using a mouldboard ploughing in order to achieve optimal seedbed conditions for crop establishment. 


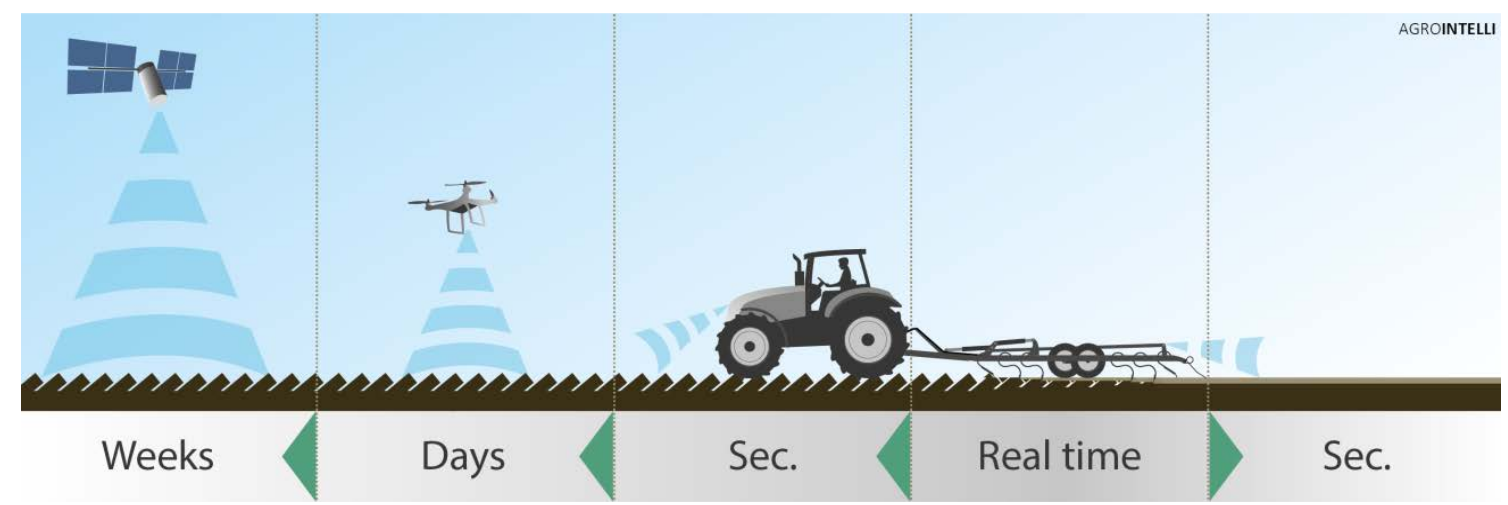

Figure 9. Sensor-based seedbed preparation, which allows collecting and analysing data at various spatial and temporal scales. 


\section{Seeeding}

Seed drills as tillage implements or individual single-, double-disc or euro coulters either with or without pressure wheels or wedge rollers are the most common coulters used for seed drilling. The total crop yield, plant development and weed competitiveness depend on seed germination and seedling emergence that, in turn, depend on seed properties, soil coverage, plant residue amount in the soil, vertical or horizontal soil compaction, seeding depth and spacing and their accuracy as well as the spatial and temporal variability of field properties (Figure 10). For instance, smaller seeds are more sensitive to the depth variations or deeper seeding leads to significant reduction in crop emergence (Håkansson et al., 2002; Kinsner et al., 1993). Therefore, it is of great importance to obtain a uniform seeding depth and soil coverage by considering the spatial and temporal variability of soil conditions, especially availability of nutrients and soil-coulter resistance as well as previous agricultural operations and their intensity and seed requirements.

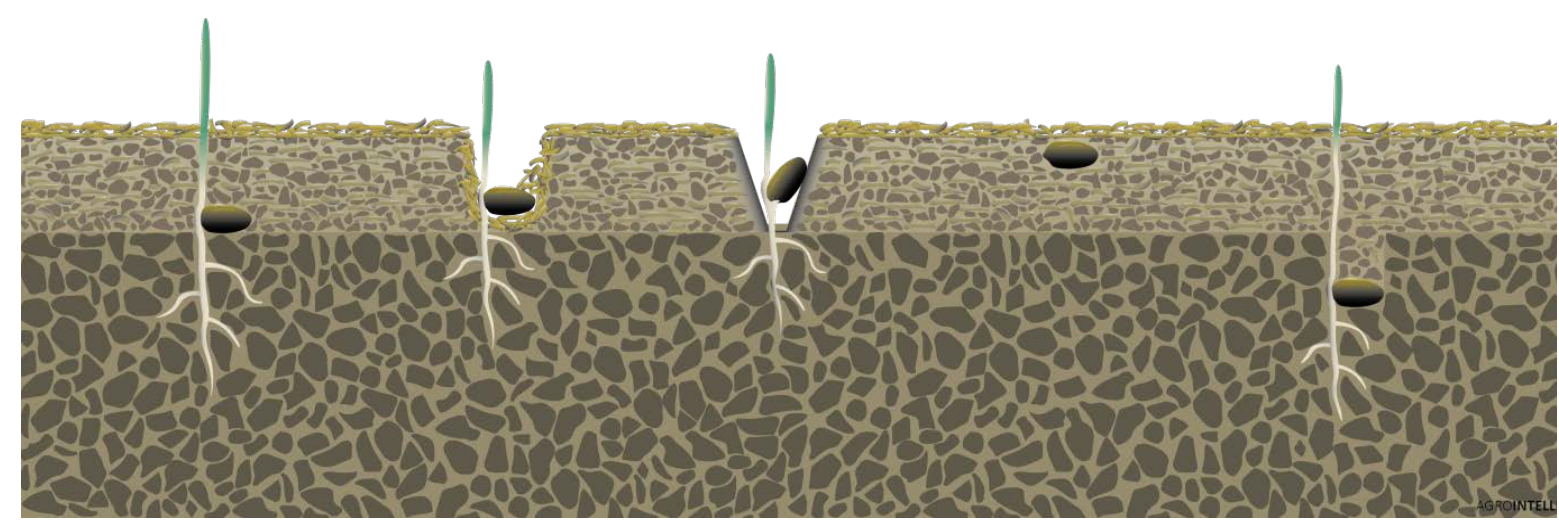

Figure 10. The desired (left) and undesired seeding (the four others): the successful seed placement in the transition zone (left); not enough soil coverage and too much plant residues; coulter-induced soil compaction and no soil coverage; too shallow and too deep seed placement prevent proper seed germination (from left to right).

In comparison to previous seed drills, which were mainly adjusted manually based on farmer's expertise and experience, the modern seed drills are equipped with individually attuned coulters that determine real-time setting in order to control coulter pressure for a required seeding depth based on the spatial data analysis of soil parameters, especially soil penetration resistance, collected using on-the-go sensors and camera as well as via soil mapping (Figure 11). The soil data generated based on previous in-field operations, especially during secondary tillage as well as operational speed have to be used in order to define the desirable seeding depth. 


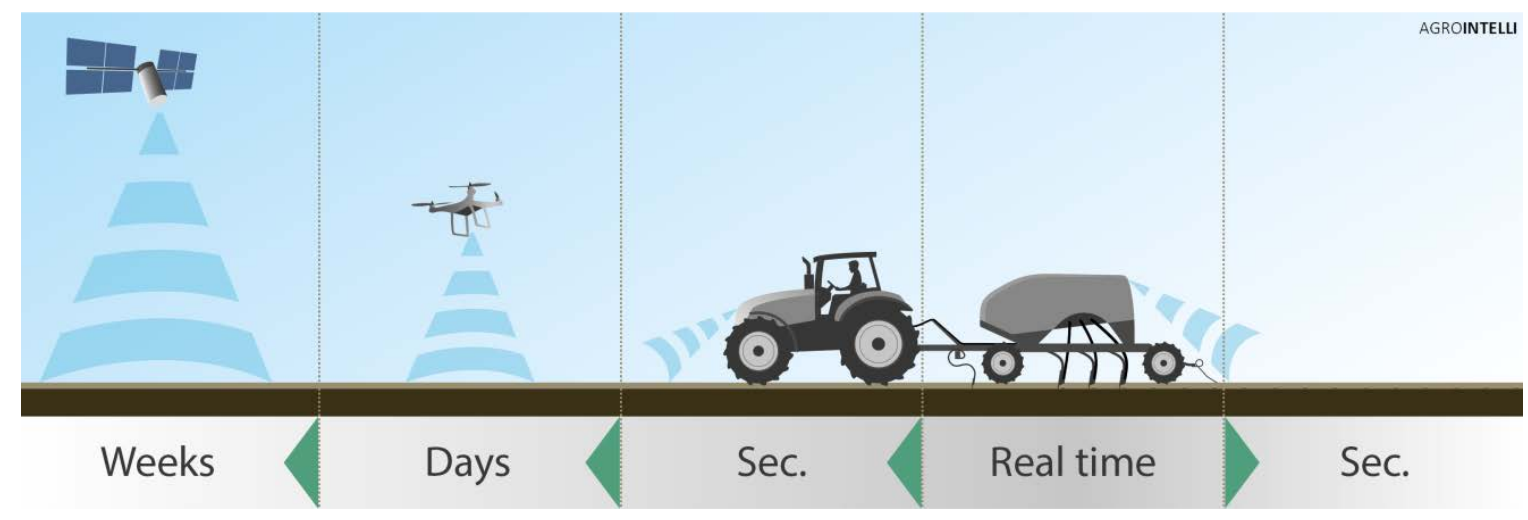

Figure 11. Sensor-based seeding operation, which allows collecting and analysing data at various spatial and temporal scales.

Thus, a coulter with a depth-controlled system can operate by taking the spatial variability of soil penetration resistance into account (Nielsen, Nørremark, \& Green, 2016). The variations of latter depend on soil parameters such as soil compaction, texture, water content and bulk density. Furthermore, by combining the site-specific depth control and seed and row spacing as well as seed dosage based on the spatial variability of soil properties (e.g. plant-available nutrients) and weed competition potential, it will be possible to improve the monitoring and estimation of soil growth potential, thus, achieving more efficient weed control and higher crop yields. Using geostatistical approaches and obtained data during automatic depth-controlled coulter operations, it would be also possible to provide assessments and recommendations on track eradicators as well as how to achieve a homogeneous seedbed by setting either manually- or automatically-controlled coulter for every agricultural field. 


\section{Mechanical weeding}

The integrated weed management such as a combination of various weed management techniques and higher application of mechanical weeding (e.g. hoeing and harrowing) are implemented more actively in order to reduce herbicide use as well as to improve crop productivity as a result of lower plant competition for nutrients. The optimal inter-row cultivation means that sufficient weed control and desired soil aggregates are achieved, while the soil surface is smooth and no negative impacts on crop development and crop injures have occurred during mechanical weeding. The row spacing cultivation is usually conducted when row crops are grown at $25-75 \mathrm{~cm}$ and as soon as weeds have been germinated (3-4 leaves) and repeated up to two-three times during the crop growing season in order to perform inter-row weed control.

The most common hoes for the mechanical weed control are a duckfoot-share (DF-share), an arrow flat cutting share and a sweep. The latter was characterised to be the most efficient for weed control at early crop growth stages than the DF-share as it causes minor lateral soil movements as well as the optimal operational depth is three time lower, thus, lower fuel consumption (Znova et al., 2017). Another approach to control weeds, especially in organic farming, is to use spring-tine weeder that can be applied after seeding and right before plant emergence. Hence, crop seedlings remain undisturbed, while early germinated weeds will be diminished.

Furthermore, the efficiency of mechanical weed control operations depends on soil conditions (e.g. moisture, structure), cultivation depth, angle and operational speed, which should be adjusted in order to achieve the minimal soil coverage of seedlings with lateral soil movements at the lowest traction force (Figure 12). During the last few years, considerable progress has been made towards higher accuracy of inter- and intra-row weeders by implementing agricultural automation systems using onthe-go vehicle-, implement- or drone-based sensors and cameras as well as software to process images and data during in-field operations, hence, enabling to adjust operational settings based on the sitespecific variability in real-time. The efficiency of weeding can be optimized by setting the depth and position of the share or tine pressure automatically based on the site-specific properties. This means that the within-field variability of soil conditions (e.g. texture, water content), previous tillage intensity and weed infestation potential during different crop growth stages has to be specified and taken into account by following intelligent weed control principles. The special attention should be paid to an autohydraulic-mechanical cleaning system and a depth-controlled system for mechanical weeding, both harrowing and hoeing, which should be implemented in order to achieve a consistent soil depth. Moreover, the distance between rows can also be justified based on the previous spatial distribution maps of crop emergence, crop health, occurred diseases, crop yields collected during automatic visual in-field operational monitoring. 

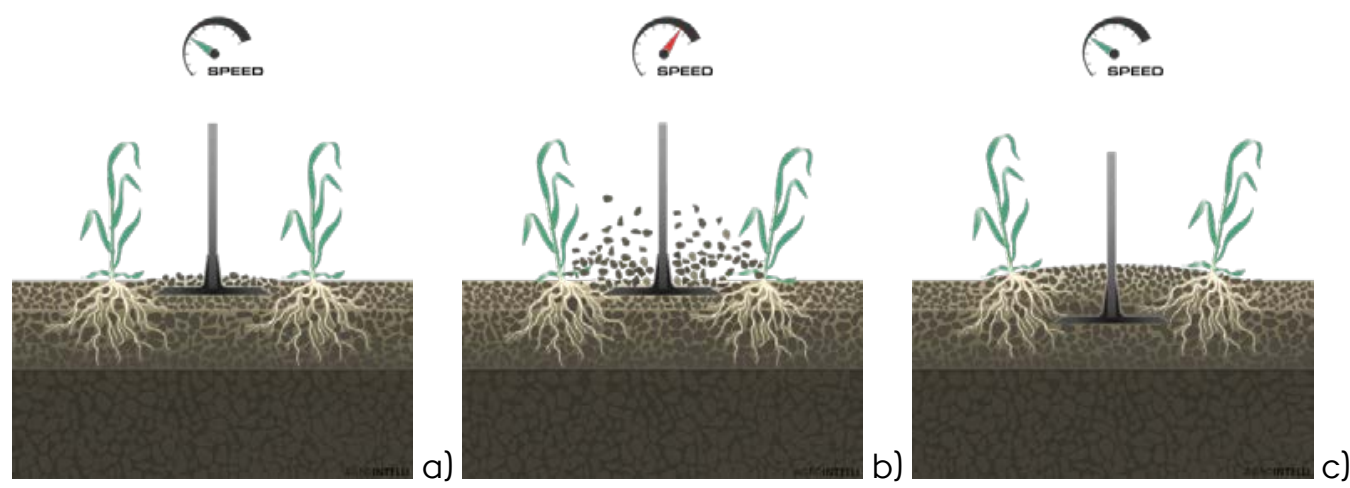

Figure 12. An example of a hoe share performance at different operational speeds and depths during weed control. The optimal speed and depth have been achieved (a); the optimal depth at higher operation speed causes high soil coverage of seedlings (b); deeper operational depths at optimal speed cause higher fuel consumption and crop injures (c). 


\section{Conclusions}

This report illustrated a vision for a new direction in agricultural development in order to produce agricultural products at minimal input costs and causing minimal both short- and long-term environmental impacts using sustainable soil management strategies. The priorities of modern agriculture are shaped by the necessity to optimise agricultural vehicles, implements and other tools in order to consider the interactions of agricultural operations at different levels as well as the spatial and temporal in-field variability that defines in-field operational patterns, intensity, strategies, and follow-up required adjustments. Automatic sensing, geostatistics, digital image processing, and further analysis of obtained data and its implementation in order to ensure that optimal operational settings have to be applied at each soil treatment process. The above-mentioned short recommendations for stakeholders can be considered as an initial step towards an action plan for farmers, consultants, NGOs and policy makers. 


\section{References}

This report presents findings and results from previously below-mentioned published PhD dissertations, which were re-used and modified for this report:

Nielsen S. K., 2017. Sensing and control of implements for site-specific field operations. Ph.D. Thesis, Agro Intelligence ApS, Faculty of Science and Technology, Department of Agroecology \& Department of Engineering, Aarhus University, Denmark. 266 pp.

Edwards G., 2015. Field Readiness and Operation Scheduling. Phd Thesis, Department of Engineering, Aarhus University. Denmark. 178 pp.

Jensen T., 2015. Intelligent Soil Tillage using Image Sensors. PhD Thesis, Faculty of Science and Technology, Aarhus University, Denmark. 142 pp.

Abrahamsen, P., \& Hansen, S. (2000). Daisy: An open soil-crop-atmosphere system model. Environmental Modelling and Software, 15(3), 313-330. https://doi.org/10.1016/S13648152(00)00003-7

AGROINTELLI (Website) Commercialization of an autonomous robot for arable plant production, viewed 14 May 2018, http://agrointelli.com/commercialrobot.html.

Bochtis, D. D., Sørensen, C. G. C., \& Busato, P. (2014). Advances in agricultural machinery management: A review. Biosystems Engineering. https://doi.org/10.1016/j.biosystemseng.2014.07.012

Brennan, E. B., \& Leap, J. E. (2014). A Comparison of Drill and Broadcast Methods for Establishing Cover Crops on Beds. HortScience, 49(4), 441-447.

Dalgaard, T., Dalgaard, R., \& Nielsen, A. H. (2002). Energiforbrug på økologiske og konventionelle landbrug. Grøn Viden - Markbrug, 260(260), 1-8.

Donatelli, M., Russell, G., Rizzoli, A. E., Acutis, M., Adam, M., Athanasiadis, I. N., ... Zerourou, A. (2010). A component-based framework for simulating agricultural production and externalities. In Environmental and Agricultural Modelling: Integrated Approaches for Policy Impact Assessment (pp. 63-108). https://doi.org/10.1007/978-90-481-3619-3_4

Durr, C., Boiffin, J., Fleury, A., \& Coulomb, I. (1992). Analysis of the variability of sugar beet (Beta vulgaris L.) growth during the early stages. II. Factors influencing seedling size in field conditions. Agronomie, 12(7), 527-535.

Edwards, G. T. C. (2015). Field readiness and operation scheduling. Mechanical Engineering. Aarhus University.

Edwards, G. T. C., Hinge, J., Skou-Nielsen, N., Villa-Henriksen, A., Sørensen, C. A. G., \& Green, O. (2017). Route planning evaluation of a prototype optimised infield route planner for neutral material flow agricultural operations.

Biosystems

Engineering,

153,

149-157. 
https://doi.org/10.1016/j.biosystemseng.2016.10.007

European Commision. (2005). Soil Atlas of Europe, European Soils Bureau Network. https://doi.org/LB37-01-744-EN-C

Garnett, T., \& Godfray, C. (2012). Sustainable intensification in agriculture. Navigating a course through competing food system priorities. Food Climate Research Network and the Oxford Martin Programme on the Future of Food, (July), 51. https://doi.org/1835-0135

Guul-Simonsen, F., Jorgensen, M. H., Have, H., \& Hakansson, I. (2002). Studies of plough design and ploughing relevant to conditions in Northern Europe. Acta Agriculturae Scandinavica Section BSoil and Plant Science, 52(2-3), 57-77.

Green, O, Schmidt, T, Pietrzkowski, RP, Jensen, K, Larsen, M \& Nyholm Jørgensen, R 2014, Commercial Autonomous Agricultural Platform - Kongskilde Robotti. in Proceedings of the Second International Conference on Robotics, Associated High-Technologies and Equipment for Agriculture and Forestry - RHEA 2014: New trends in mobile robotics, perception and actuation for agriculture and forestry. pp. 351-356, Madrid, Spain, 21/05/2014.

Håkansson, l., Myrbeck, Å., \& Etana, A. (2002). A review of research on seedbed preparation for small grains in Sweden. Soil and Tillage Research, 64(1-2), 23-40.

Jensen, T., Karstoft, H., Green, O., \& Munkholm, L. J. (2017). Assessing the effect of the seedbed cultivator leveling tines on soil surface properties using laser range scanners. Soil and Tillage Research, 167, 54-60. https://doi.org/10.1016/j.still.2016.11.006

Jones, J. W., Hoogenboom, G., Porter, C. H., Boote, K. J., Batchelor, W. D., Hunt, L. A., ... Ritchie, J. T. (2003). The DSSAT cropping system model. In European Journal of Agronomy (Vol. 18, pp. 235-265). https://doi.org/10.1016/S1161-0301(02)00107-7

Keskin, S. G., Khalilian, A., Han, Y. J., \& Dodd, R. B. (2011). Variable-depth Tillage based on Georeferenced Soil Compaction Data in Coastal Plain Soils. International Journal of Applied Science and Technology, $7(2)$.

Kinsner, W., Gamby, G., Froese, R. a., \& Tessier, T. (1993). A fuzzy seeding depth monitoring and control system. Communications, Computers and Power in the Modern Environment, IEEE, 276-281.

Morrison, J. E., \& Gerik, T. J. (1985). Planter Depth Control: II. Empirical Testing and Plant Responses. TRANSACTIONS of the ASAE, 28(6), 1744-1748.

Natsis, A., Papadakis, G., \& Pitsilis, J. (1999). The Influence of Soil Type, Soil Water and Share Sharpness of a Mouldboard Plough on Energy Consumption, Rate of Work and Tillage Quality. Journal of Agricultural Engineering Research, 72(2), 171-176.

Nielsen, S. K., Nørremark, M., \& Green, O. (2016). Sensor and control for consistent seed drill coulter depth. Computers and Electronics in Agriculture, 127, 690-698. https://doi.org/10.1016/j.compag.2016.07.029

Petersen, C. T., Nielsen, M. H., Rasmussen, S. B., Hansen, S., Abrahamsen, P., Styczen, M., ... Zhang, Y. (2016). Jordbearbejdningens indflydelse på pesticidudvaskning til markdrœn. Miljøstyre/sen, København., 
$1-135$.

RECARE (Website) New RECARE report published 'Measures for Preventing, Mitigating and Remediating Soil Threats in Europe - a Literature Review', https://www.recare-hub.eu/news/152-new-recarereport-publised-measures-for-preventing-mitigating-and-remediating-soil-threats-in-europe-aliterature-review. Accessed 12 May 2018.

Russell, E. W. (1961). Soil Conditions and Plant Growth (9th ed.). London: Longmans, Green and Company.

Sartori, L., Basso, B., Bertocco, M., \& Oliviero, G. (2005). Energy use and economic evaluation of a three year crop rotation for conservation and organic farming in NE Italy. Biosystems Engineering, 97(2), 245-256.

Schjønning, P., Lamandé, M., Keller, T., Pedersen, J., \& Stettler, M. (2012). Rules of thumb for minimizing subsoil compaction. Soil Use and Management, 28(3), 378-393. https://doi.org/10.1111/j.14752743.2012.00411.x

Schjønning, P., Lamandé, M., Tøgersen, F. A., Arvidsson, J., \& Keller, T. (2008). Modelling effects of tyre inflation pressure on the stress distribution near the soil-tyre interface. Biosystems Engineering, 99(1), 119-133. https://doi.org/10.1016/j.biosystemseng.2007.08.005

SoilCare (Website) REPORT 06 - D2.1 - A review of soil improving cropping systems - v1 - WENR Oenema, https://www.soilcare-project.eu/downloads/public-documents/soilcare-reports/75report-06-d2-1-a-review-of-soil-improving-cropping-systems-wenr-oene-oenema. Accessed 12 May 2018.

Terranimo $®$ (Website) International, Terranimo $®$ is a model for prediction of the risk of soil compaction due to agricultural field traffic https://www.terranimo.dk. Accessed 11 May 2018.

Znova, L., Melander, B., Lisowski, A., Klonowski, J., Chlebowski, J., Edwards, G. T. C., ... Green, O. (2017). A new hoe share design for weed control: measurements of soil movement and draught forces during operation. Acta Agriculturae Scandinavica, Section B - Soil \& Plant Science, 4710(September), 1-10.

All illustrations are made by Ole Green and Keld Bertelsen and owned by AGROINTELLI (http://agrointelli.com). All reproduction of these illustrations must be made with complete reference to this report. 
DCA - National Centre for Food and Agriculture is the entrance to research in food and agriculture at Aarhus University (AU). The main tasks of the centre are knowledge exchange, advisory service and interaction with authorities, organisations and businesses.

The centre coordinates knowledge exchange and advice with regard to the departments that are heavily involved in food and agricultural science. They are:

Department of Animal Science

Department of Food Science

Department of Agroecology

Department of Engineering

Department of Molecular Biology and Genetics

DCA can also involve other units at $\mathrm{AU}$ that carry out research in the relevant areas. 


\section{SUMMARY}

This report provides an overview on new technologies for integrate sustainable and resilient management practices in arable ecosystems for advanced farmers, consultants, NGOs and policy makers. By following sustainable soil management strategies, which consider the site- and field-specific parameters and agricultural machinery's improvements, it is possible to maximize production and income, while reducing negative environmental impacts and human health issues induced by agricultural activities as well as improving food and soil quality in short- and long-terms. This report also illustrates the importance to combine a system approach for plant production by assessing field readiness, managing in-field traffic management, implementing the sitespecific controlled as well as sensor-controlled seedbed preparation, seeding, and weeding. Hence, allowing to estimate future field and crop parameters based on various sensors measurements of previous and current field and crop parameters, which is a required data input in order to optimize agricultural machinery's performance.

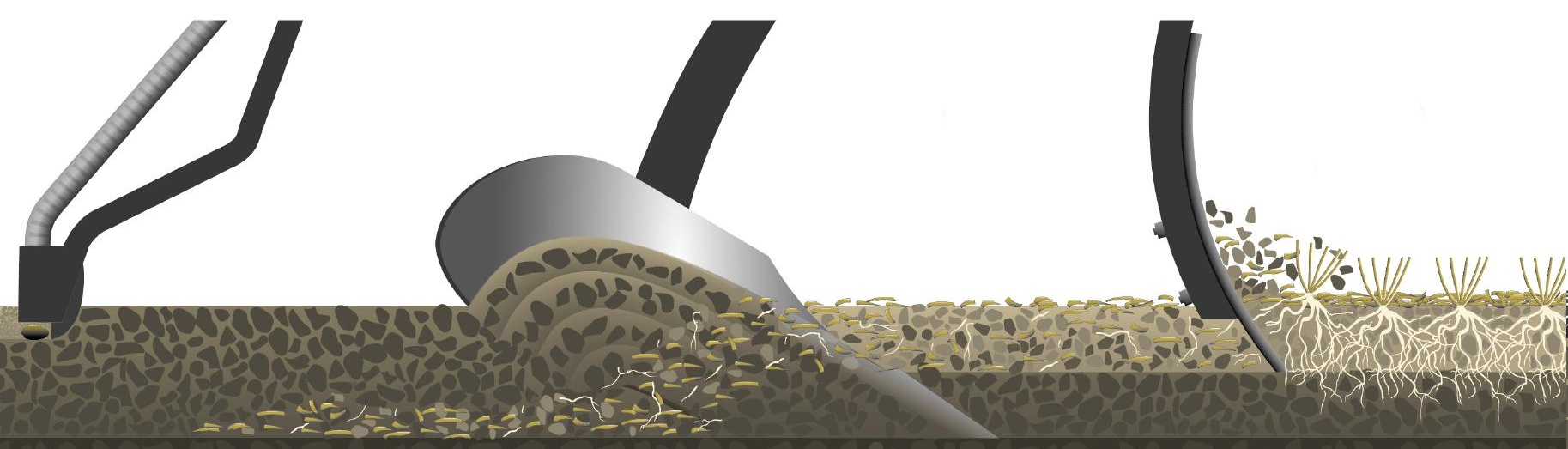

